\title{
O ACERVO HISTÓRICO DA COMARCA DE BRAGANÇA: PRESERVAÇÃO DOCUMENTAL E MEMÓRIAS DO PODER JUDICIÁRIO DO PARÁ
}

\section{THE HISTORICAL COLLECTION OF THE REGION OF BRAGANÇA: DOCUMENTARY PRESERVATION AND MEMORIES OF THE JUDICIARY OF PARÁ}

\section{Magda Nazaré Pereira da Costa*}

\begin{abstract}
Resumo: A partir do estudo de caso da Comarca de Bragança, no Pará, este artigo analisa o processo de organização e preservação documental, pelo qual passa o acervo histórico dessa unidade judiciária estadual. Desde $2017 \mathrm{com}$ a assinatura do convênio de cooperação entre o Tribunal de Justiça do Pará (TJPA) e a Universidade Federal do Pará (UFPA), atividades de conservação preventiva são realizadas junto ao setor de arquivo do Fórum de Bragança, onde cerca de cem mil registros de natureza cível, criminal e administrativa, datados de meados do século XIX até os dias atuais, encontravam-se acumulados em condições inapropriadas. Com mais de três anos de vigência, o convênio resultou, dentre outras coisas, em um projeto de extensão vinculado a Faculdade de História, do campus de Bragança, que coordena o tratamento da documentação de valor permanente e através do qual a memória institucional e social do Poder Judiciário paraense vem sendo recuperada em função das pesquisas de caráter histórico, produzidas a partir de então, que têm nessa documentação sua principal fonte de informação.
\end{abstract}

Palavras-chave: Preservação Documental. Memória. Poder Judiciário. Bragança-PA.

Abstract: From the case study of the region of Bragança, in Pará, this article analyzes the process of organization and documentary preservation, through which passes the historical collection of this state judicial unit. Since 2017 with the signing of the cooperation agreement between the Court of Justice of Pará (TJPA) and the Federal University of Pará (UFPA), preventive conservation activities are carried out with the archive sector of the Bragança Forum, where about one hundred thousand records of a civil, criminal and administrative nature, dated from the mid-nineteenth century to the present day , were accumulated under inappropriate conditions. With more than three years of validity, the agreement resulted, among other things, in an extension project linked to the Faculty of History, of the Bragança campus, which coordinates the treatment of documentation of permanent value and through which the institutional and social memory of the Judiciary of Pará has been recovered due to the historical research, produced since then, which have in this documentation their main source of information.

\footnotetext{
* Doutoranda do Programa de Pós-Graduação em História da Universidade Federal do Pará (UFPA). Mestre em História Social pela Universidade Federal do Pará (UFPA). Graduada em História pela Universidade Federal do Pará (UFPA). Professora da Faculdade de História da Universidade Federal do Pará, campus de Bragança. E-mail: magpcosta@yahoo.com.br.
} 
DE BRAGANÇA: ...

Keywords: Documentary Preservation. Memory. Judicial Power. Bragança-PA.

Recebido em: 01/08/2020 Aceito em: 05/09/2020 


\section{INTRODUÇÃO}

Com a promulgação da Lei 8.159 de 8 de janeiro de 1991 que estabelece a Política Nacional de Arquivos, novas diretrizes foram estabelecidas no Brasil quanto à preservação dos documentos arquivísticos e à relevância dos arquivos públicos e privados como instituições de custódia dos mesmos. Por décadas, a realidade de grande parte desses espaços foi caracterizada pelo acúmulo desordenado e pela ausência de mecanismos racionais de gestão dos registros produzidos e/ou recebidos por eles.

No entanto, vale ressaltar, que no que se refere, especificamente, aos arquivos públicos e às instituições públicas que possuem arquivos, ainda hoje, mesmo sob a tutela do Estado, tal cenário de descaso não acusou mudanças significativas. Perpetua-se a inexistência de um sistema eficiente de gestão de documentos e de instrumentos de pesquisa que permitam a recuperação otimizada da informação e de ações precisas voltadas para resguardar a materialidade documental.

Reflexo de uma política de ampliação e de garantia do direito à informação, prevista na Constituição brasileira de 1988, a dita "Lei de Arquivos", ratificava os debates e fundamentava as determinações relativas ao acesso democrático a informação, disponível a todo e qualquer indivíduo, como condição precípua ao exercício da cidadania. E entre seus resultados destacavam-se, sobretudo, a impressão de novas concepções e novos valores a respeito da preservação dos documentos arquivísticos.

Assim, considerados parte do patrimônio cultural material da nação, com a retomada da experiência democrática nos anos 1980, os documentos públicos e, em especial, aqueles de caráter histórico, no geral, mais suscetíveis à deterioração em função da ação implacável do tempo, demandam, quando em tal condição, urgentes e objetivas ações preventivas, posto sua importância enquanto suportes de referência à identidade e à memória de uma dada sociedade. A preservação do patrimônio documental e a democratização do acesso às informações nele contidas, ajudam a construir a história de um lugar, de suas gentes e de suas instituições a partir de uma concepção diversa e plural.

Diante disso, considerando a importância da preservação da documentação do Judiciário para a compreensão da estrutura de poder da justiça no Brasil, das suas 
articulações com outros setores da hierarquia político-administrativa do Estado e, sobretudo, da sua relação com a sociedade local, estabelecendo e executando mecanismos de controle, fiscalização e penalidade sobre sujeitos e espaços específicos, é que apresentamos aqui uma breve análise acerca do acervo histórico da Comarca de Bragança, no Pará.

Enquanto unidade do Judiciário estadual, em atividade desde o ano de 1839, esta Comarca tem revelado ao longo do processo de organização e preservação do seu arquivo permanente, iniciado em 2017, fragmentos de vidas diversas, assim como também, teias de relações engendradas pelos agentes e representantes da Justiça nas localidades que compreendiam sua circunscrição e, principalmente, pelos indivíduos que coercitivamente eram levados às delegacias, às subdelegacias e aos juízos para dar explicações sobre os fatos denunciados ou serem julgados pelos crimes a que estavam supostamente envolvidos.

Apontada como uma das comarcas mais antigas do estado, produtora e detentora de um volume documental significativo para a história do Poder Judiciário no Pará e na região amazônica, essa unidade judiciária possui um setor de arquivo instalado nas dependências do Fórum de Bragança, que paradoxalmente, em função da nulidade de seu gerenciamento, permaneceu por vários anos, em condições inapropriadas e, que contribuíram sobremaneira, para a aceleração do processo de deterioração de uma parcela de seus registros.

Para o desenvolvimento desta pesquisa, portanto, tomamos ainda como fundamental compreender a relação entre arquivo, preservação, memória e identidade, enquanto categorias analíticas e, seus principais fundamentos teóricoepistemológicos.

Por fim, para tornar a análise do processo de preservação daquele acervo inteligível ao leitor, apresentamos primeiramente um breve histórico sobre a Comarca de Bragança e a relevância dos registros produzidos por ela, para o estudo da História e da Memória do Judiciário em quase dois séculos de funcionamento e suas ações pelas vilas, freguesias e povoados da região fronteiriça entre o Pará e o Maranhão; para em seguida discorrermos sobre o processo de organização e preservação documental propriamente dito pelo qual vem passando aquele unidade judiciária nos últimos anos e os resultados obtidos, até o momento, a partir dele. 


\title{
2 O PODER JUDICIÁRIO DO PARÁ E A HISTÓRIA DA COMARCA DE BRAGANÇA E SEU ACERVO
}

Criada em 1839, através da Lei Provincial № 17 de 09 de setembro, a Comarca de Bragança, surge em meio a um contexto de reconfiguração da estrutura judiciária do Pará, determinada pelo então Presidente da Província Bernardo de Souza Franco. Naquela ocasião, organizava-se uma nova Divisão das Comarcas e Termos da Província do Pará, iniciada ainda em 1833, em conformidade ao Código do Processo Criminal do Império e, com o intuito de melhor atender as necessidades administrativas e judiciárias de diversas localidades. (PARÁ, 1839a).

Diante da grande extensão territorial da Província e do parco contingente populacional que sabia ler e escrever a fim de atender a contento às exigências $e$ atribuições dos cargos relativos às funções do Judiciário, o Pará, que até então era composto por apenas três Comarcas (da Capital, do Baixo Amazonas e do Alto Amazonas), enfrentava, sobretudo, em áreas mais longínquas, críticas e resistências à atuação da justiça por aquelas paragens, que não raro era acusada de inábil e inoperante. No Termo de Turiassú, por exemplo, localizado na fronteira com a Província do Maranhão e, que até o ano de 1838 fazia parte da Comarca da Capital ${ }^{1}$, seus habitantes requeriam insistentemente o desmembramento da localidade do restante do Pará, alegando dificuldades na comunicação e no repasse de recurso por parte da sede da Comarca, isto é, a cidade de Santa Maria de Belém, cabeça do Termo de mesmo nome. Tal como expunha a administração provincial à Assembleia Legislativa.

\begin{abstract}
Podeis porem decretar a creação de mais duas outraz Comarcas na Província, e eu vos requizito com particularidade a elevação dos Termos de Bragança e Turi-assú, á Comarca. Esta medida he da primeira necessidade para dár um centro jurídico mais próximo ao Termo de Turi-assú e para tirar aos pouquíssimos habitantes deste Districto os pretextos com que requererão a Assemblea Geral a desmembração do seu território do da Provincia do Pará. (PARÁ, 1839b).
\end{abstract}

Em atenção ao apelo da Presidência, os "senhores membros" daquela Assembleia em suas legislaturas seguintes definem, portanto, uma nova organização

\footnotetext{
1 Compunham a Comarca da Capital no ano de 1838, os seguintes termos: da Cidade de Santa Maria de Belém, da Vila de Turiassú, da Vila de Bragança, da Vila de Cintra, da Vila de Vigia, da Vila de Monsará, da Vila de Nossa Senhora da Conceição da Cachoeira, da Vila de Muaná, da Vila do Equador, da Vila de Ourém, da Vila de Cametá, da Vila de Tocantins, da Vila de Oiras e da Vila de Melgaço.
} 
para a Justiça da maior Província do Estado imperial brasileiro, que a partir daquele momento se constituiria em quatro Comarcas em razão da homologação da lei referida inicialmente que instaura a Comarca de Bragança.

Com uma localização estratégica por abranger uma importante área fronteiriça com o Maranhão ${ }^{2}$, como vimos enfatizando, a nova Comarca, além de supostamente atender os problemas apontados em Turiassú, também passaria a gerenciar, dentre outras coisas, conflitos e questões recorrentes naquela região relativos à demarcação de territórios, à fuga de negros e negras escravizados, além de representar um mecanismo de "controle e fiscalização" da circulação e dos comportamentos de homens livres e libertos, de índios e de caboclos sediciosos cabanos $^{3}$, que também estabeleceram ali importante rota de fuga. Fato que, apesar das distâncias e dificuldades, provavelmente, levou a justiça a agir de maneira mais enérgica nessa região sob a alegação de garantir a "segurança pública e individual".

A despeito do papel relevante que esta unidade do judiciário local assume desde o contexto de sua criação, faz-se imperioso salientar que, no que tange a história do Poder Judiciário no Pará, há por outro lado um curioso e relativo silêncio em relação a existência da Comarca de Bragança entre alguns autores que se dispuseram a abordar tal tema. Ernesto Cruz (1974), tomando por base os Relatórios e Falas dos Presidentes da Província, também consultados por nós, salienta que por volta de 1840 já havia no Pará quatro Comarcas, porém sem informar quais seriam elas. No campo da magistratura, Silvio Hall de Moura (1974) e Almir de Lima Pereira (1998), ao tecer um panorama do Judiciário no Pará no período de 1823-1873, ignoram por completo, o processo que resultou na instalação da Comarca de Bragança no fim dos anos 1830, levando a crer que o Pará naquele período ainda se constituía de apenas três Comarcas como nos idos de 1833.

Atualmente a Comarca de Bragança integra a $5^{\underline{a}}$ região Judiciária do Tribunal de Justiça do Pará (TJPA), cujo polo localiza-se no município de Capanema, a $50 \mathrm{~km}$ de Bragança. Tendo celebrado seus 180 anos de funcionamento no ano de 2019, essa unidade encontra-se instalada no Fórum "Desembargador Augusto Rangel de

\footnotetext{
2 A Comarca de Bragança compreendia no século XIX o Termo de Bragança, sendo composta pela Vila de Bragança, como a cabeça do Termo, juntamente com as Freguesias de São José do Piriá, Gurupi e Vizeu, além do Termo de Turiassú, formado por quatro distritos de Paz.

${ }^{3} \mathrm{O}$ termo se refere aos participantes da Cabanagem, movimento ocorrido na então Província do Pará no ano de 1835.
} 
Borborema" desde 1976 e ainda é considerada uma das mais dinâmicas da referida região. Fato que ocasionou em 2015 uma mudança em sua estrutura interna, quando foi instalada mais uma vara judiciária de competência criminal. A Resolução n. 18 de 02 de dezembro do Tribunal de Justiça do Pará (TRIBUNAL DE JUSTIÇA DO ESTADO DO PARÁ, 2015a) alterou a Lei estadual n. 7768 de 20 de dezembro de 2013 (GOVERNO DO PARÁ, 2013), atribuindo uma nova configuração para a Comarca de Bragança, como observamos abaixo.

Quadro 1 - Comarca de Bragança.

\begin{tabular}{|c|l|}
\hline Vara/Juizado & \multicolumn{1}{|c|}{ Competências } \\
\hline $\begin{array}{c}\text { 1a Vara Cível } \\
\text { e Empresarial }\end{array}$ & $\begin{array}{l}\text { Processar e julgar os feitos da Fazenda Pública e } \\
\text { Infância e Juventude }\end{array}$ \\
\hline $\begin{array}{c}2^{\text {a }} \text { Vara Cível } \\
\text { e Empresarial }\end{array}$ & $\begin{array}{l}\text { Processar e julgar os feitos de Família e Registros } \\
\text { Públicos }\end{array}$ \\
\hline $\begin{array}{c}3^{\text {a }} \text { Vara } \\
\text { Criminal }\end{array}$ & $\begin{array}{l}\text { Processar e julgar crimes de toda natureza, inclusive } \\
\text { os relativos à violência contra a Mulher (Lei Maria da } \\
\text { Penha) }\end{array}$ \\
\hline $\begin{array}{c}\text { Juizado } \\
\text { Especial Cível } \\
\text { e Criminal }\end{array}$ & $\begin{array}{l}\text { Conciliar, julgar e executar as causas cíveis de menor } \\
\text { complexidade e infrações penais de menor potencial } \\
\text { ofensivo pelo Poder Judiciário. }\end{array}$ \\
\hline
\end{tabular}

Fonte: Resolução ㄲo 18 (TRIBUNAL DE JUSTIÇA DO ESTADO DO PARÁ, 2015a), 02/12/2015 TJPA.

Portanto, em função do seu elevado fluxo de trabalho a Comarca de Bragança, produziu, e ainda produz, uma grande quantidade de documentos gerados no cotidiano de suas atividades, relativos as questões administrativas e jurisdicionais demandadas pelos municípios de Bragança e Tracuateua ${ }^{4}$, que atualmente a integram.

No Fórum que sedia esta unidade da justiça estadual existia, no entanto, como dito antes, apenas uma pequena sala de arquivo que reunia de maneira desordenada e em condições inapropriadas um vasto acervo de documentos orgânicos estimado em torno de mais de 100 mil unidades documentais entre processos cíveis e criminais, inventários, testamentos, cartas precatórias, livros de sentença e demais registros relativos ao Poder Judiciário oriundos dos antigos Juízos, das varas e dos cartórios

\footnotetext{
${ }^{4}$ Município localizado a $15 \mathrm{~km}$ de Bragança.
} 
que também compunham aquela Comarca. Neste local, os acervos permanente, intermediário e corrente foram acumulados por vários anos e confundiam-se uns com os outros, se deteriorando e dificultando não só a consulta voltada a pesquisa histórico-documental, mas sobretudo, aquela que visa atender os interesses dos cidadãos circunscritos e o trabalho administrativo e judicial desenvolvido ali.

Exposta, por longo tempo, às intempéries, aos fungos e a todo e qualquer tipo de sujidade entre poeira e excrementos de insetos e animais, a massa documental existente no setor de arquivo, data de meados do século XIX até os dias atuais e, originalmente, não possuía arranjo ou classificação alguma, posto a total desconsideração do princípio da proveniência e do respeito aos fundos (SCHELLENBERG, 2002), visto que uma parcela considerável encontra-se fragmentada, dispersa ou ocupando a mesma caixa independente de sua natureza e ordem cronológica.

Figura 1 - Arquivo do Fórum de Bragança.

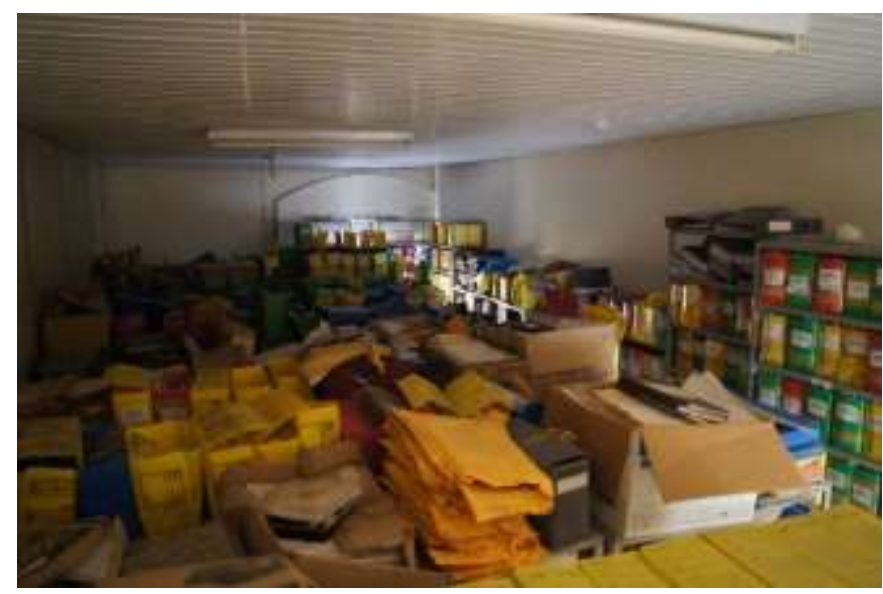

Fonte: Autor (2017), acervo PRODOC. 
Figura 2 - Arquivo do Fórum de Bragança.

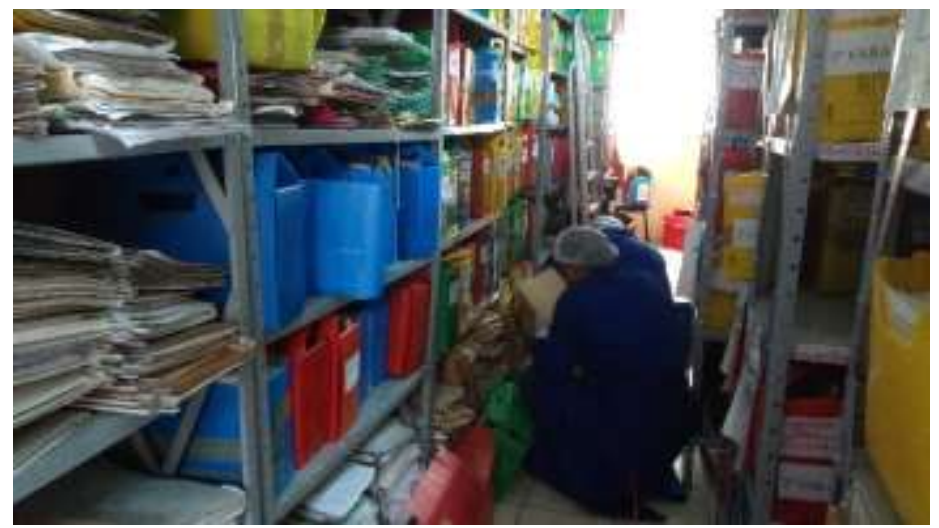

Fonte: Autor (2018), acervo PRODOC.

No bojo desse acervo estão registradas informações concernentes à organização e às estratégias de poder do Estado, através das ações que chegavam, e chegam, à instância do judiciário, bem como, diversas memórias e histórias de sujeitos da sociedade civil levados à justiça em função de determinadas atitudes, conflitos e comportamentos repreendidos ou condenáveis em uma determinada época e circunstância. O universo do arquivo judiciário, embora represente uma memória institucional, conforme destaca Arlette Farge (2009, p. 31), também "capta a cidade em flagrante delito", isto é, "a driblar a ordem" estabelecida; além de trazer à tona em suas narrativas, fragmentos de múltiplas vidas, reveladas na dinâmica daquele espaço e do seu entorno e no cotidiano de sua população.

A falta de gestão que contemplasse, portanto, o material produzido pelas Comarcas do Pará, por longo tempo provocou nas unidades judiciárias do interior do Estado um cenário preocupante e dramático em relação a esse patrimônio. E em se tratando, em especial, de Bragança, para além das condições precárias de acondicionamento, parte da documentação foi possivelmente perdida durante mudanças da sede do Fórum ou em razão do não-controle de usuários internos e externos que tinham acesso indiscriminado ao acervo. Sabe-se ainda, que outro montante de documentos foi enviado em anos anteriores para o Tribunal de Justiça em Belém e hoje, encontra-se sob a guarda do Centro de Memória da Amazônia $(\mathrm{CMA})^{5}$.

\footnotetext{
${ }^{5}$ Localizado em Belém, o Centro de Memória da Amazônia (CMA) é uma unidade administrativa e acadêmica vinculada à Reitoria da Universidade Federal do Pará.
} 
Diante disso, o documento mais antigo identificado, até o momento, em Bragança, trata-se de um testamento correspondente ao ano de 1865. No entanto, entre o conjunto dos bens materiais pertencentes ao seu arquivo permanente chama a atenção, a expressiva quantidade de processos crimes relacionados a estupro, defloramento, rapto e sedução, referentes às primeiras décadas da República brasileira (final do século XIX e início do século XX).

Dada a precariedade geral dos arquivos e das instituições arquivísticas, como ressaltamos acima e, a consequente escassez da existência de fontes, e as significativas dificuldades de acesso à elas, a fim de permitirem a investigação do passado de instituições e de sujeitos específicos a partir das agências de poder que submetiam ou a que estavam submetidos direta ou indiretamente, iniciativas em prol da organização e da preservação de acervos, como a que analisamos aqui, a partir de um arquivo Judiciário, tem promovido no Pará, especificamente, a oportunidade de contribuir para um processo de transformação de um cenário recorrente no Brasil e, sobretudo, no interior da Amazônia, onde carecemos muito mais de políticas de gestão de documentos por parte das organizações públicas e privadas, visando a acessibilidade ampla e irrestrita da informação ao cidadão e o fomento às pesquisas científicas como forma de garantia do direito à memória, ao conhecimento histórico e a valorização dos arquivos.

No TJPA essa preocupação foi despertada em 2010, a partir de parcerias firmadas com instituições de caráter histórico, cultural e de ensino e pesquisa no âmbito da implementação do Programa Nacional de Gestão Documental e Memória do Poder Judiciário - Proname ${ }^{6}$ (CONSELHO NACIONAL DE JUSTIÇA, 2020a), no Pará. E, juntas têm se empenhado na organização e recuperação dos acervos judiciários permanentes existentes na capital e no interior do estado.

Assim as atividades desenvolvidas em Bragança no acervo daquela Comarca são também resultantes deste contexto e, cuja experiência passamos a discutir.

\footnotetext{
6 O Proname foi criado em 2008 e é resultante do termo de cooperação firmado entre o CONARQ Conselho Nacional de Arquivos e o CNJ - Conselho Nacional de Justiça. O objetivo do programa é implementar uma política de gestão documental que atenda as peculiaridades do Poder Judiciário brasileiro.
} 


\section{PRESERVAÇÃo DOCUMENTAL: PRESSUPOSTOS TEÓRICOS E METODOLÓGICOS}

No campo de atuação da arquivística no Brasil, vários são os autores que contribuem com as discussões e orientações em torno dos princípios e das práticas da preservação documental. No manual "Como fazer conservação preventiva em arquivos e bibliotecas", Norma Cassares (2000), apresenta aos que se lançam aos desafios de tal atividade, a seguinte definição, "preservação: é um conjunto de medidas e estratégias de ordem administrativa, política e operacional que contribuem direta ou indiretamente para a preservação da integridade dos materiais". (CASSARES, 2000, p. 12).

Seguindo a mesma linha de análise, Lygia Guimarães (2007) defende que a preservação corresponde à implantação de uma política geral, a partir da qual é possível planejar as áreas de conservação preventiva e de restauração dos documentos arquivísticos. Para ela, "o planejamento de preservação possui ações que visam retardar e prolongar a vida útil dos acervos culturais, através da prevenção e do combate à sua deterioração". (GUIMARÃES, 2007, p. 47).

A preservação dos documentos, portanto, não pode ser compreendida como uma ação isolada e pontual voltada exclusivamente à manutenção física dos materiais existentes nos acervos, sob o risco de propagarmos um entendimento simplista e limitado acerca deste processo.

Contudo, na contramão do que vem sendo debatido, a realidade de grande parte dos arquivos públicos ou dos setores de arquivo dos órgãos do governo espalhados pelo Brasil, revela uma situação generalizada de "deficiência no processamento técnico" de preservação da matéria-prima encontrada em seus acervos (JARDIM, 1995). Sem a padronização do gerenciamento da informação e a suposta falta de recursos para o agenciamento e a qualificação de pessoal apropriado para o desempenho do trato documental, grande parte destas repartições nunca apresentou ao longo de sua história, algum tipo de planejamento racional voltado ao recolhimento e/ou a avaliação dos registros produzidos ou recebidos na prática de suas atividades-fim. Segundo José Maria Jardim (1995), tal realidade é considerada um dos principais fatores que levam à "sacralização" dos documentos, os quais sem seleção adquirem automaticamente, com o passar do tempo, o status de documentos 
históricos. Condição esta, que em tese, impõe a manutenção da integridade física desses bens e o seu arquivamento compulsório.

Fato que também contribui para sustentar um discurso recorrente nesses lugares em relação a provável incompatibilidade entre a preservação adequada dos ditos documentos, a disponibilidade de estrutura e de espaço apropriado para o seu acondicionamento e o desenvolvimento satisfatório das funções administrativa e jurídica da instituição, em geral, produtora ainda de volumosos registros físicos. Argumento que, na verdade, apenas reitera o ínfimo e eventual uso social e cultural que se faz até hoje das informações produzidas no domínio da administração pública. (JARDIM, 1995).

Sob essas condições, os arquivos permanentes, em particular e, seus documentos históricos, são reduzidos, na maioria das vezes, a meros repositórios de uma memória institucional. Sustentáculos da construção de uma identidade nacional e, que contempla muito mais as expectativas dos agentes do poder do que da própria sociedade.

Numa perspectiva ampla, o cerne da preservação requer, por conseguinte, atenção aos interesses e objetivos relacionados à missão da instituição produtora do material arquivístico ou daqueles que detêm sua custódia, mas sem desconsiderar que enquanto processo, ela se torna sobretudo, como evidencia Aluísio de Castro (2010), uma construção cultural, um ato político, isto é, intencional. Enquanto seleção, é imprescindível ressaltar, que a preservação configura uma espécie de legitimação das práticas e representações de grupos sociais, a ela de alguma forma, relacionados.

Pelo exposto, entendemos que a preservação dos documentos de arquivos ou a falta dela, não se configura, em nenhum momento, em um ato ingênuo ou aleatório. Se a sua prática faz parte de um planejamento maior referente à gestão da informação e dos documentos de um determinado órgão, capaz de construir, ratificar ou modificar uma determinada memória, a sua inoperância e o descaso atribuído aos registros cronologicamente mais antigos, também resultam, de certa forma, num negligenciamento ostensivo, tornando-se um complicador para a recuperação e o acesso democrático à informação, que quando incorporado ao cotidiano de uma repartição, corrobora um silêncio de concepções díspares e o não enfrentamento de memórias híbridas que permitam, eventualmente, questionar os mesmos sujeitos e estruturas hierárquicas de poder em que tais órgãos estão inseridos. 
Assim sendo, na condição de "lugares de memória", como classificou Pierre Nora (1993), os arquivos resguardam fragmentos e/ou meios de memória através de suportes materiais que, segundo o autor, nos são exteriores. E por não apresentarem uma memória espontânea, a constituição de seus acervos acaba por se tornar reflexo das políticas e práticas de preservação que the são aplicadas.

Portanto, sendo a priori uma construção ideológica, os arquivos, de acordo com Nora (1993), são "lugares" onde grupos aparentemente coesos tendem a reconhecer indivíduos iguais e idênticos, visto que através deles seus ideais e suas formas de interpretação do mundo podem ser cristalizados. Concepção esta que alguns anos antes já era rebatida por Michel Pollak (1989) ao afirmar que "a referência ao passado serve para manter a coesão dos grupos e das instituições que compõem uma sociedade, para definir seu lugar respectivo, sua complementariedade, mas também as oposições irredutíveis". (POLLAK, 1989, p. 9).

Desse modo, as chamadas "memórias subterrâneas", como se refere Pollak aos relatos sufocados nos porões dos velhos arquivos e identificadas nas entrelinhas das narrativas dos documentos oficias, quando resgatadas do "esquecimento", fomentam a reinterpretação de uma determinada época e lugar e se transformam em ferramentas de valorização da identidade local e regional, de memórias plurais e de construção de histórias de lutas, conflitos, resistências e sobretudo, de diversidades.

\section{ORGANIZAÇÃO E PRESERVAÇÃO DOS DOCUMENTOS DE BRAGANÇA: SUPORTES DE MEMÓRIAS JUDICIÁRIAS NUMA COMARCA DO INTERIOR}

Ao considerar a importância do acesso e da preservação da documentação judiciária para a expansão da informação, para a garantia de direitos e para a produção do conhecimento relativo à estrutura, às estratégias de poder da justiça no Brasil e sua relação com a sociedade, o Conselho Nacional de Justiça (CNJ), reiterando o que já previa a Constituição brasileira de 1988 (BRASIL, 1988) em seu Art. 216, através do termo de cooperação n. 22/2008 (CONSELHO NACIONAL DE JUSTIÇA, 2008) firmado com o Conselho Nacional de Arquivos (CONARQ), lança em fins daquele ano, o Proname.

Voltado a todos os órgãos judiciais do país das instâncias federal e estadual, o objetivo específico deste programa é implementar uma política de gestão de documentos que atenda as peculiaridades do Poder Judiciário, estabelecendo normas 
e padrões aos processos de produção, tramitação e preservação dos registros gerados no cotidiano das atividades administrativas e judiciárias dos órgãos ligados àquele Poder.

Por gestão de documentos no âmbito do Judiciário, a Resolução no 324 (CONSELHO NACIONAL DE JUSTIÇA, 2020b) de 30 de junho de $2020^{7}$ define que:

É o conjunto de procedimentos e operações técnicas referentes à produção, à tramitação, ao uso, à avaliação e ao arquivamento de documentos e processos recebidos e tramitados pelos órgãos do Poder Judiciário no exercício das suas atividades, inclusive administrativas, independentemente do suporte de registro da informação. (CONSELHO NACIONAL DE JUSTIÇA, 2020b, p. 4).

Associado a isso, o referido instrumento normativo institui ainda diretrizes e normas relativas à gestão da memória institucional judiciária, compreendendo como tal:

O conjunto de ações e práticas de preservação, valorização e divulgação da história contida nos documentos, processos, arquivos, bibliotecas, museus, memoriais, personalidades, objetos e imóveis do Poder Judiciário, abarcando iniciativas direcionadas à pesquisa, à conservação, à restauração, à reserva técnica, à comunicação, à ação cultural e educativa. (CONSELHO NACIONAL DE JUSTIÇA, 2020b, p. 4).

Sob a prerrogativa de ser uma instância de poder autônoma, o Judiciário institui com esse programa suas próprias ferramentas de gestão documental e memória. São criados a partir de então, planos de classificação e tabelas de temporalidades, que passam a estabelecer diretrizes voltadas a padronização da classificação, da descrição, da avaliação e do recolhimento de seus documentos. Além, de lançar um olhar mais atencioso "à promoção da cidadania, por meio do acesso ao [seu] patrimônio arquivístico, museográfico, bibliográfico, histórico e cultural”. (CONSELHO NACIONAL DE JUSTIÇA, 2020b, p. 2-3).

Contudo, considerando talvez as dificuldades e as limitações dos órgãos judiciários em relação ao trato documental, o CNJ faculta aos mesmos, "o auxílio de órgãos ou entidades de caráter histórico, cultural, social e universitário", através do estabelecimento de convênios, a fim de proporcionar e assegurar a "disponibilização de acesso, a descrição do acervo e a difusão da informação contida na documentação

\footnotetext{
7 Esta Resolução substituiu a Recomendação CNJ no 37 de 15 de agosto de 2011 (CONSELHO NACIONAL DE JUSTIÇA, 2011), que juntamente com a Recomendação ํo 46 de 17 de dezembro de 2013 (CONSELHO NACIONAL DE JUSTIÇA, 2013), constituíam até então, os principais instrumentos normativos do Proname.
} 
judicial". (CONSELHO NACIONAL DE JUSTIÇA, 2013, p. 2; CONSELHO NACIONAL DE JUSTIÇA, 2020b, p. 10).

No Pará, o Tribunal de Justiça do Estado, que desde 2006 vem trabalhando em prol da organização e da implantação efetiva de sua política de gestão documental - Portaria no 1607/2006-GP (TRIBUNAL DE JUSTIÇA DO ESTADO DO PARÁ, 2006) - as parcerias com as instituições cooperantes, previstas pelo Proname, já eram uma realidade. Com a assinatura do convênio 005/2007 firmado com a Universidade Federal do Pará, o TJPA inaugura uma série de cooperações firmadas com instituições de ensino e de cultura, a fim de garantir um suporte teórico e técnico no trato do material arquivístico, sobretudo, de caráter permanente das Comarcas da capital e do interior ${ }^{8}$.

Será, portanto, em função de tais experiências, que em 2017 o Tribunal de Justiça reafirma sua parceria com a UFPA, através da Faculdade de História do campus de Bragança, celebrando com essa Instituição de Ensino Superior, o convênio de cooperação $\mathrm{n}^{\circ} 021$ de 07 de junho, tendo por finalidade:

[...] a disponibilização da documentação que compõe o Acervo Histórico de documentos judiciais do TJ/PA, localizado na Comarca de Bragança, anterior ao ano de 1970, para que seja tratado, catalogado, controlado e preservado, garantindo o acesso e a manutenção da memória social às gerações futuras, além da realização de pesquisas científicas na construção do conhecimento da história das relações sociais e culturais da Amazônia. (TRIBUNAL DE JUSTIÇA DO ESTADO DO PARÁ, 2006, p. 1).

Conforme as determinações da Resolução № 324/2020 - CNJ, a classificação dos documentos do Judiciário de valor permanente é definida através do corte cronológico estabelecido pelos tribunais. Desse modo, considerando a promulgação do Decreto ํo 2342 de 6 de agosto de 1873 (BRASIL, 1873) que autoriza a instalação do Tribunal de Relação do Pará e a necessidade "de resguardar a memória dos [seus] primeiros 97 anos" é que no TJPA foram classificados como de guarda permanente todos os processos e demais documentos administrativos produzidos até o ano de 1970, estando os demais classificados como intermediários ou correntes - Portaria $\mathrm{n}^{0}$ 2436/2015-GP. (TRIBUNAL DE JUSTIÇA DO ESTADO DO PARÁ, 2015b).

\footnotetext{
8 Desde 2007 o Tribunal de Justiça do Pará estabeleceu os seguintes convênios: a) 2007: UFPA, objeto principal: documentação da Comarca de Belém; b) 2013: Universidade Federal do Oeste do Pará (UFOPA), objeto principal: documentação da Comarca de Santarém; c) 2015: Associação 5 de agosto, objeto principal: documentação da Comarca da Vigia; d) 2017: UFPA, campus de Bragança, objeto principal: documentação da Comarca de Bragança; e) 2018: Universidade Federal do Sul e Sudeste do Pará (UNIFESSPA), objeto principal: documentação da Comarca de Marabá.
} 
Todavia, em se tratando, particularmente, do convênio relativo à Comarca de Bragança, este configura exceção ao que, via de regra, fora determinado pelo Tribunal do Pará e seguem os demais convênios. Atendendo uma importante demanda apresentada pela Faculdade de História (FAHIST), em 26 de outubro de 2018, as instituições cooperadas assinam o $1^{0}$ Termo Aditivo ao convênio 021/2017 (TRIBUNAL DE JUSTIÇA DO ESTADO DO PARÁ, 2018), estendendo até o ano de 1988 o marco-cronológico da documentação a ser tratada e custodiada pela UFPA. As décadas de 1970 e 1980 correspondem a um importante período da história política nacional, regional e local e a preservação e o acesso aos documentos do Poder Judiciário relativos a essa época representam relevante oportunidade de pesquisa acadêmico-científica e de difusão da história e da memória institucional e social relacionadas às ações da Justiça durante o Regime Militar nas localidades jurisdicionadas por Bragança.

Vale ressaltar que pelo mesmo aditivo foi incorporado também àquele convênio a documentação permanente da Comarca de Ourém $^{9}$, permitindo aos pesquisadores e a qualquer outro cidadão, esquadrinhar diferentes temas e episódios da história de tão relevante e estratégica região do Pará.

A oficialização da cooperação TJPA-UFPA, via Faculdade de História resultou, portanto, em 2017 no Projeto Preservação Documental e Organização dos Arquivos Históricos das Comarcas de Bragança e de Ourém no Nordeste do Pará $(\mathrm{PRODOC})^{10}$, cujo objetivo é desenvolver atividades de conservação preventiva nos acervos permanentes daquelas Comarcas instalados nos Fóruns "Desembargador Augusto Rangel de Borborema" e "Juiz Oscar Lopes da Silva", respectivamente.

\footnotetext{
9 Pertencente também a $5^{\underline{a}}$ Região Judiciária do Estado do Pará, a Comarca de Ourém está localizada a $102 \mathrm{~km}$ de Bragança.

10 Até 2018 o PRODOC intitulava-se "Preservação documental e organização do acervo histórico do Fórum de Bragança", passando a receber a denominação atual, após a homologação do primeiro termo aditivo do convênio 021/2017-TJPA em fins daquele ano, quando foi incorporada ao mesmo convênio a documentação pertencente à Comarca de Ourém-Pa. Sob a minha coordenação, o PRODOC, corresponde a um projeto cadastrado junto à Pró-Reitoria de Extensão da UFPA (PROEX), e desde 2017 vem sendo desenvolvido com apoio do Programa Institucional de Bolsas de Extensão (PIBEX).
} 
Figura 4 - Logotipo do PRODOC.

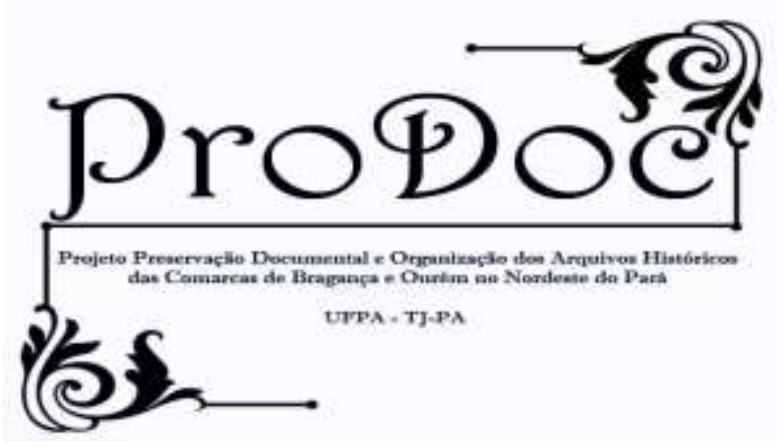

Fonte: Universidade Federal do Pará (2019), acervo PRODOC.

Com uma equipe técnica formada por docentes e discentes da Faculdade de História dos campi de Bragança e de Capanema da UFPA, além de colaboradores vinculados ao quadro de servidores do Tribunal de Justiça do Pará, o PRODOC, em Bragança, realiza suas atividades nas dependências do Fórum da cidade, ocupandose das principais fases do processo de organização e preservação da documentação histórica produzida pela Justiça naquela jurisdição.

Nesse sentido, tais são as etapas de trabalho do projeto que visam assegurar uma intervenção objetiva, racional e sistemática junto ao setor de arquivo da Comarca de Bragança:

a) Identificação: corresponde à localização e reconhecimento dos documentos jurídicos e administrativos produzidos até o ano de 1988;

b) Higienização: consiste na limpeza e na desmetalização dos documentos com a retirada de pó e de corpos estranhos;

c) Acondicionamento: equivale a organizar os documentos em novas caixas etiquetadas e numeradas de maneira progressiva e respeitando o "princípio da proveniência".

d) Classificação: refere-se à leitura e identificação do material conforme o tipo documental e a natureza da ação julgada e, cujos dados passam a compor uma ficha catalográfica;

e) Digitalização: consiste em criar um novo suporte eletrônico ao documento, através da técnica da migração, isto é, da conversão dos dados registrados no papel em bits. (CONARQ, 2015).

Além dessas etapas, com o auxílio de um servidor do Fórum, o PRODOC realiza também o cadastro dos documentos na Plataforma LIBRA, pertencente ao 
Sistema de Gestão de Processos Judiciais do Poder Judiciário do Pará. Através dela, o Tribunal de Justiça do Estado faz o registro e o controle do que é produzido em suporte físico e digital conforme a dinâmica de seus serviços jurisdicionais.

Embora esse trabalho vise a recuperação de um acervo específico, que aparentemente representa tão somente uma dada memória institucional, a preservação dos arquivos do Poder Judiciário evidencia, na verdade, a multiplicidade e a riqueza da natureza de suas fontes, além de revelar a sua importância para a construção e a propagação da história e da memória de um lugar. Farge (2009), destaca que apesar dessa documentação possuir o mesmo formato e a mesma estrutura, os autos lavrados pelos escrivães e tomados por delegados, subdelegados e/ou por juízes e promotores têm nas histórias que sustentam as ações que lhes dão origem, sentidos e significados diferentes. Segundo ainda a autora, os arquivos judiciários correspondem, em grande medida, a um dos conjuntos documentais mais "brutalmente" conservados em bibliotecas e arquivos departamentais.

E é esse emaranhado de documentos que, quando preservado de maneira racional, nos possibilita - tal como citado anteriormente - trazer à tona um universo variado de "memórias subterrâneas", como queria Pollak (1989). Em outras palavras, elas designam, as experiências e vozes silenciadas de sujeitos excluídos socialmente, registradas nas narrativas dos autos e, muitas vezes, "esquecidas" nas versões oficiais das histórias das instituições produtoras dos acervos.

Durante muito tempo os interiores dos arquivos institucionais serviram de matéria-prima para a construção de "memórias coletivas" (HALBWACHS, 1990), enquanto sinônimo de "memórias nacionais" e, nesse sentido, ratificavam a ideologia de grupos sociais privilegiados e aparentemente coesos, em detrimento dos demais. Todavia, atualmente, é possível observar na essência do material arquivístico teias complexas de relações e de sujeitos e grupos diversificados, características de uma época e de um espaço, em particular. Através delas são descortinadas concepções de mundo, padrões culturais, religiosos, comportamentais e estruturas de poder, assim como também são identificadas as circunstâncias e os perfis daqueles que ousaram resistir ou transgredir às regras impostas.

Para Heloisa Bellotto (2014, p. 133), os arquivos constituem elementos fundamentais para uma "melhor compreensão entre a identidade cultural de uma comunidade e a evolução de sua história, e o desenvolvimento das relações entre o 
cidadão e o Estado". A promoção e o reconhecimento da identidade cultural através dos arquivos é, portanto, uma questão de cidadania, na medida em que a preservação e o acesso aos bens custodiados pelas instituições arquivísticas ou que possuem um setor de arquivo permitem à sociedade, trazer à tona diferentes memórias relacionadas à história e à cultura de um lugar.

E em Bragança, um dos municípios mais antigos do Pará, com 407 anos $^{11}$, elementos da cultura e da identidade local têm sido recuperados através da organização do acervo do judiciário estadual produzido durante os quase dois séculos de funcionamento da Comarca sediada naquela cidade. As ações do Poder Judiciário no Pará e a expansão da Justiça pelo interior estão diretamente relacionadas aos movimentos de resistência e contestação de uma determinada "ordem social" propagada ao longo do século XIX e revestida de um discurso de "progresso" a partir do século XX, já sob o regime republicano brasileiro.

Desse modo, considerando os acontecimentos políticos da época e a própria natureza documental do acervo aqui analisado, as pesquisas de caráter histórico desenvolvidas com esse material têm trazido à baila temas e objetos de estudo, que denotam muito mais do que feitos dos representantes do Estado e administradores da Justiça nas localidades circunscritas à Comarca de Bragança. Vários estudos têm identificado as estratégias de controle e as tentativas de fiscalização e penalidade impostas a uma sociedade, ao mesmo tempo em que revelam a fragilidade das instâncias policial e judiciária diante das ações e circunstâncias constantes nos autos.

Ao nos debruçarmos sobre esta documentação, emergem histórias de homens e mulheres pobres, negros e negras livres, libertos e escravizados, caboclos e caboclas, migrantes nordestinos, imigrantes europeus, lavradores, pescadores, pequenos comerciantes, curandeiros e curandeiras, desocupados e "vadios", que por algum motivo ousaram burlar as regras e padrões de comportamento de uma época e, acabaram inquiridos e julgados por uma Justiça conduzida por tantos outros personagens, geralmente, homens, brancos, de condição social elevada e representados por magistrados, escrivães, médicos, peritos, boticários e outros, considerados "cidadãos idôneos".

Diante disso, até o momento, estão sendo produzidos trabalhos em nível de graduação e pós-graduação sobre os seguintes temas: i) as concepções de Justiça e

11 O município de Bragança foi fundado em 08 de julho de 1613. 
as relações e estratégias de poder estabelecidas na sociedade de Bragança no alvorecer do século XX; ii) o crime e os criminosos indiciados e julgados pela prática de violência sexual e contra a mulher ao longo do século XIX e XX; iii) o uso e as atribuições das provas materiais anexadas aos autos dos processos crimes de ordem sexual; iv) o universo de (des)organização do espaço urbano e rural da cidade de Bragança e a relação entre seus habitantes e transeuntes no limiar dos séculos XIX e $X X ; v)$ as práticas de feitiçaria e pajelança identificadas pela Justiça em fins do século $X I X$; vi) a influência político-administrativa de juízes e escrivães no processo de constituição e julgamento dos crimes; vii) a influência e a interferência de médicos e peritos nos desdobramentos dos processos a partir da análise dos autos de exame de corpo de delitos; viii) a disputa de poder entre personalidades e instituições de referências políticas e religiosas de Bragança.

\section{CONCLUSÃO}

O processo de organização e preservação do arquivo da Comarca de Bragança que ora esboçamos, permanece em andamento. $O$ convênio que 0 regulariza teve em 18 de junho de 2020, um segundo Termo Aditivo homologado, prorrogando seu prazo de vigência até junho de 2022. Quando finalizados os trabalhos, a documentação tratada deve passar a custódia temporária da Universidade Federal do Pará através da Faculdade de História e do Laboratório de História e Patrimônio Cultural na Amazônia (LABHIST) no campus de Bragança.

Com a conclusão das atividades de conservação preventiva, pretende-se disponibilizar aos servidores do Fórum local, aos pesquisadores e à sociedade em geral do Município de Bragança, uma expressiva e significativa variedade de informação oriunda da documentação permanente produzida por aquela unidade judiciária. E assim lançar luz à possibilidade e, sobretudo, à necessidade, de mudanças de atitudes e perspectivas por parte do poder público e dessa mesma sociedade em relação à manutenção e à criação de arquivos e, a consequente preservação e valorização de documentos arquivísticos como parte de seu patrimônio cultural e material.

Sob a ótica da ciência histórica, os documentos dos arquivos do Judiciário são considerados atualmente, como vimos, imprescindíveis à análise das complexas 
estruturas sociais e políticas estabelecidas em uma determinada época. Eles trazem à tona, variadas memórias recuperadas a partir dos registros da escrita acelerada do escrivão no transcorrer da inquirição das partes envolvidas e das testemunhas arroladas, assim como também das sentenças proferidas pelos juízes.

Reafirmar a variedade de memórias e de histórias imersas no universo do arquivo do Fórum da Comarca de Bragança, significa, portanto, reconhecer o quão imperiosa e, acreditamos também, exitosa, se tornaram, no Pará, as parcerias interinstitucionais firmadas entre os órgãos produtores dos documentos e as entidades especializadas, a fim de garantir às gerações atuais e futuras, o amplo e irrestrito acesso à tão importante material arquivístico do Poder Judiciário de valor histórico. A preservação racional e objetiva destes documentos representa, sobretudo, a garantia de um princípio constitucional fundamental e imperioso ao cidadão, que é o direito à informação, relativo às instituições públicas brasileiras, sejam elas das esferas local, estadual ou federal.

\section{REFERÊNCIAS}

BELLOTTO, Heloisa Liberalli. Arquivos: estudos e reflexões. Belo Horizonte: Ed. UFMG, 2014.

BRASIL. Decreto no 2.342, de 6 de agosto de 1873. Crêa mais sete Relações no Imperio e dá outras providencias. Rio de Janeiro: Império do Brasil, 1873.

CASSARES, Norma Cianflone; MOI, Claudia. Como fazer conservação preventiva em arquivos e bibliotecas. Colaboração: Claudia Moi. São Paulo: Arquivo do Estado: Imprensa Oficial, 2000. v. 5.

CASTRO, Aluisio Arnaldo Nunes de. A preservação documental no Brasil: notas para uma reflexão histórica. Revista Acervo. Rio de Janeiro, v. 23, n. 2, p. 31-46, jul./dez. 2010.

CONARQ. Diretrizes para a implantação de repositórios arquivísticos digitais confiáveis - RDC-Arq. Rio de Janeiro: Arquivo Nacional, 2015.

CONSELHO NACIONAL DE JUSTIÇA. Gestão documental. CNJ, Brasília, DF, 2020a. Disponível em: https://www.cnj.jus.br/programas-e-acoes/gestaodocumental/. Acesso em: 14 abr. 2020.

CONSELHO NACIONAL DE JUSTIÇA. Recomendação no 37, de 15 de agosto de 2011. Recomenda aos Tribunais a observância das normas de funcionamento do Programa Nacional de Gestão Documental e Memória do Poder Judiciário - 
Proname e de seus instrumentos. [Brasília, DF]: Presidência, 2011. Disponível em: https://atos.cnj.jus.br/atos/detalhar/846. Acesso em: 14 abr. 2020.

CONSELHO NACIONAL DE JUSTIÇA. Recomendação $n^{\circ}$ 46, de 17 de dezembro de 2013. Altera a Recomendação ${ }^{\circ} 37$, de 15 de agosto de 2011. Brasília, DF: Presidência da República, 2013.

CONSELHO NACIONAL DE JUSTIÇA. Resolução no 324, de $\mathbf{3 0}$ de junho de 2020. Institui diretrizes e normas de Gestão de Memória e de Gestão Documental e dispõe sobre o Programa Nacional de Gestão Documental e Memória do Poder Judiciário Proname. [Brasília, DF]: Presidência, 2020b. Disponível em:

https://atos.cnj.jus.br/atos/detalhar/3376. Acesso em: 10 jul. 2020.

CONSELHO NACIONAL DE JUSTIÇA. Termo de cooperação técnica no 22/2008. Termo de cooperação técnica que entre si celebram o Conselho Nacional de Justiça e o Conselho Nacional de Arquivos, para fins que especifica (Processo № 333.818). Brasília, DF: CNJ, 2008. Disponível em: https://www.cnj.jus.br/wpcontent/uploads/2019/11/TCOT_022_2008.pdf. Acesso em: 14 abr. 2020.

CRUZ, Ernesto. O poder judiciário do Pará: 3o período político. v. 1. Belém: Governo do Estado do Pará, 1974.

FARGE, Arlette. O sabor do arquivo. São Paulo: EdUSP, 2009.

GOVERNO DO PARÁ. Lei n. 7.768, de 20 de dezembro de 2013. Transforma os Termos Judiciários de Inhangapi e Aveiro em Comarcas; cria as Comarcas de Anapú e Ipixuna do Pará, a 3 ${ }^{\underline{a}}$ Vara da Infância e Juventude da Capital, transforma o Centro Integrado de Atendimento ao Adolescente - C.I.A.A, criado pela Lei no 6.579, de 11 de setembro de 2003, na $4^{a}$ Vara da Infância e Juventude da Comarca da Capital; cria na $2^{\mathrm{a}}$ entrância uma Vara nas Comarcas de Bragança, Capanema, Itaituba, Tucumã, Xinguara e transforma o Juizado Especial de Itaituba em Vara; cria, na 1a entrância, uma Vara nas Comarcas de Canaã dos Carajás, Curionópolis e Dom Eliseu; cria os cargos que especifica e dá outras providências. Belém: Governo do Estado, 2013.

GUIMARÃES, Lygia; BECK, Ingrid. Conservação e Restauração de documentos em suporte de papel. In: GRANATO, Marcus; SANTOS, Cláudia Penha dos; ROCHA, Cláudia Regina Alves da. (org.). Conservação de acervos. Rio de Janeiro: MAST, 2007. p. 45-60.

HALBWACHS, Maurice. A memória coletiva. São Paulo: Edições Vértice, 1990.

JARDIM, José Maria. A invenção da memória nos arquivos públicos. Revista Ciência da Informação. [S. I.], v. 25, n. 2, p. 1-13, 1995.

MOURA, Silvio Hall de. Elementos para a história da magistratura paraense. Belém: UFPA, 1974. 
NORA, Pierre. Entre memória e história: a problemática dos lugares. Proj. História, São Paulo, n. 10, p. 7-28, dez. 1993.

PARÁ. Discurso recitado pelo Exm. Sr. Dr. Bernardo de Souza Franco, Prezidente da Província do Pará quando abrio a Assembléa Legislativa Provincial no dia 15 de Agosto de 1839. Pará: Typographia de Santos \& menor, 1839b.

PARÁ. Lei Provincial n 17 de 09 de setembro de 1839. Cria a Comarca de Bragança. Pará: [S. n.], 1839a.

PEREIRA, Almir de Lima. A história do poder judiciário no Pará. Belém: Tribunal de Justiça, 1998.

POLLAK, Michael. Memória, esquecimento, silêncio. Estudos históricos, Rio de Janeiro, v. 2, n. 3, p. 3-15, 1989.

SCHELLENBERG, Theodore R. Arquivos modernos. Rio de Janeiro: FGV Editora, 2002.

TRIBUNAL DE JUSTIÇA DO ESTADO DO PARÁ. 1 Termo de Aditivo ao Convênio de cooperação n. 021/2017/TJPA de 26 de outubro de 2018. Que entre si celebram o Tribunal de Justiça do Pará e a Universidade Federal do Pará: campus de Bragança. Belém: Tribunal de Justiça do Estado do Pará, 2018.

TRIBUNAL DE JUSTIÇA DO ESTADO DO PARÁ. Portaria n 1607 de 19 de outubro de 2006. Institui no Poder Judiciário do Estado do Pará o Programa de Gestão de Documentos (GD). Belém: Tribunal de Justiça do Estado do Pará, 2006.

TRIBUNAL DE JUSTIÇA DO ESTADO DO PARÁ. Portaria $\mathbf{n}^{\circ} \mathbf{2 4 3 6}$, de 24 de junho de 2015. Estabelece o ano de 1970 como corte cronológico de processos judiciais deste egrégio tribunal, para fins de gestão documental. Belém: Tribunal de Justiça do Estado do Pará, 2015b.

TRIBUNAL DE JUSTIÇA DO ESTADO DO PARÁ. Resolução n. 18 de 02 de dezembro de 2015. Dispõe sobre a instalação da Vara Criminal da Comarca de Bragança, redefine as competências, renomeia as Varas e dá outras providências. Belém: Tribunal de Justiça do Estado do Pará, 2015a.

UNIVERSIDADE FEDERAL DO PARÁ. PRODOC na Semana Nacional dos Arquivos do TJPA. [Bragança]: UFPA, 2019. Disponível em: http://eprodoc.ufpa.br/index.php/ultimas-noticias/107-prodoc-na-semana-nacionaldos-arquivos-do-tjpa. Acesso em: 14 abr. 2020. 